\title{
The Art of Healing - Core Values and Goals of Medicine, Nursing and Healthcare
}

\author{
Muhammad Jawad Hashim
}

Healthcare professionals such as physicians, nurses, pharmacists, therapists, and other caregivers including traditional healers share a remarkable calling i.e. healing. While the human body has an innate capacity for self-repair, the process can be aided by practitioners skilled in the art of healing. This art rests upon core values of kindness, compassion, and a desire to help others. Healers respect the patient as a person.

Certain essential skills are needed to render this craft. The journey towards becoming a healer begins with learning. Sustained by a spark of curiosity, the apprentice never stops acquiring knowledge. Lifelong learning is the hallmark of a true professional. No external forces such as licensure or recertification are needed to compel the healer to read. Self-directed learning comes from a desire to provide best possible care. Treatments and tests are chosen from carefully conducted research. Clinical decisions should not be based on personal opinions, anecdotal experience, case reports or chart reviews without control groups. Systematic reviews and meta-analyses of randomised controlled trials can keep us from repeating the tragic history of medicine. Shunning bizarre and brutal 'remedies', such as bloodletting, we now seek treatments that are proven effective and safe.

The quest for knowledge is visible in the pursuit of perfection. Meticulousness, attention to small details, going the extra mile, and staying beyond duty are the hallmarks of a committed caregiver. Excellence becomes routine. This obsession with details pays off in patient safety, comfort and better outcomes. Whether it is handwashing for universal precautions or antibiotic selection for stewardship, healthcare providers who take the extra effort achieve better results. They protect resources by avoiding waste, and handling supplies with utmost care.

The power to heal rests on trust. Patients seek us with a tentative trust in our abilities, talent and truthfulness. They trust that we will recommend treatments without

\footnotetext{
Department of Family Medicine, College of Medicine and Health Sciences, UAE University, Al-Ain, UAE

Correspondence: Dr. Muhammad Jawad Hashim, Department of Family Medicine, College of Medicine and Health Sciences, UAE University, Al-Ain, UAE

E-mail:physicianthinker@gmail.com

Received: October 18, 2018; Accepted: November 26, 2018
}

conflicts of interest, fee-splitting, kickbacks or commissions. We avoid gifts from the pharmaceutical industries to avoid their influence on our prescribing. The fiduciary relationship between patients and physicians remains sacrosanct. Healers sacrifice self-interest.

Healing is touching the heart. For many patients, a down-to-earth attitude, in which patients are treated as family, opens their hearts. Doctors, nurses, and professionals who provide direct care must touch the patient. This physical contact is simultaneously routine and reverential. When doctors touch their patients, a bond of healing starts to build. The ritual of looking at the patient and palpating areas of pain releases endorphins and other healing hormones. Indeed, not infrequently, patients feel better simply by visiting a caring professional. ${ }^{1}$ Instruments such as the stethoscope and the ultrasound probe are but extensions of the physician's hands. When using the stethoscope, the healer listens intently. Tuning out external noise and one's own breathing, the healer can zone in on the rhythmic cycle of the patient's internal valves and chambers. This concentrated focus enables a virtual visualisation of the anatomy and pathology within the patient's body. Yet, the healer has not forgotten the human inside and pauses frequently to inform the patient of the findings as well as the next step. This conversation, during physical examination and clinical procedures, has a direct healing effect on the patient.

Time is healer's helper. In most acute illnesses, from infections to burns and injuries, time is needed to heal. ${ }^{2}$ Our role is supportive: manage symptoms such as pain, nausea, dryness and anxiety, as well as prevent complications. A true healer avoids burdensome treatment. Whether it is artificial feeding in dementia or life support in terminal illness, the humane healer prefers to spend time with the patient, discussing preferences, ideas and fears. What are the patient's goals and expectations? It is perhaps more important to understand the impact of metastatic cancer on the family than to ascertain the genomic mutations within the tumor. ${ }^{3} \mathrm{~A}$ generalistic approach is holistic and patient-centered. It considers cost, convenience, cultural acceptance and the community. Instead of a narrow focus on the diseased organ, the patient's preferences take centre stage. Treatment decisions are discussed including the option of watchful waiting with follow-up. Continuity of relationship through clinic visits or telephone contacts 
sustains hope. Healing is listening with compassion and empathy. Empathy is connecting with another human being by trying to understand their plight. This is what transforms the professional into a healer.

The goal of healthcare is not merely to sustain cellular processes, but to nurture life and enable self-healing. Medical science sheds light on what works; the art of healing guides us to what is worth doing. Healing is an art. It is the art of listening compassionately, empathising, touching and building a caring relationship with a fellow human being during sickness and suffering. Healing alleviates suffering. But then again, suffering is existential to the healer.

\section{REFERENCES}

1. Qidwai W, Ali SS, Ayub S, Ayub S. Healing during physicianpatient consultation. J Coll Physicians Surg Pak 2005; 15:689-92.

2. Chaudhry TA, Shaikh F, Ahmad K. Healing of cornea following an electric burn. $J$ Coll Physicians Surg Pak 2012; 22:533-5.

3. Muneeb A, Jawaid $H$, Khalid N, Mian A. The art of healing through narrative medicine in clinical practice: A reflection. Perm J 2017; 21.

\section{..........}

